\title{
BIMBINGAN TEKNIS PEMAHAMAN TENTANG RECOVERY REFRIGERANT DAN EFEK REFRIGERANT PADA KESEHATAN DAN LINGKUNGAN PADA IKM TEKNISI AC DAN KULKAS KEDIRI RAYA
}

\author{
Hadi Rahmad', Riswan Eko Wahyu Susanto ${ }^{2}$, Saiful Arif ${ }^{3}$, Zulfa Khalida ${ }^{4}$ \\ 1,2,3,4 Politeknik Negeri Malang \\ e-mail: hadi.rahmad@polinema.ac.id ${ }^{1}$
}

\begin{abstract}
Abstrak - Refrigerant yang lepas ke lingkungan akan merusak alam karena kandungan chlorine yang terdapat di dalamnya. Selain itu refrigerant juga merupakan zat yang toxic dan akan merusak system syaraf pusat dan mengakibatkan efek negative cardiovascular. Untuk mengurangi pelepasan refrigerant ke lingkungan maka dalam pengabdian kepada masyarakat ini teknisi AC dan kulkas dipilih sebagai mitra. Teknisi AC dan kulkas merupakan orang yang langsung terjun ke lapangan dan bersentuhan langsung dengan refrigerant pada AC dan kulkas. Dengan menjadikan teknisi AC menjadi mitra maka diharapkan kegiatan ini akan meningkatkan pemahaman teknisi tentang refrigerant dan diharapkan dengan peningkatan pengetahuan teknisi diharapkan dapat mengurangi lepasnya refrigerant. Dalam pengabdian kepada masyarakat ini teknisi AC dan kulkas di Kediri raya diberikan bimbingan melalui kegiatan offline dan juga online untuk memberikan pemahaman teknisi tentang refrigerant. Bimbingan teknis offline dilakukan di tempat kerja dengan mengikuti protocol kesehatan yang ketat dalam masa pandemic covid 19. Untuk pemberian materi yang tidak menggunakan peralatan, teknisi diberikan via zoom meeting untuk menjangkau semua teknisi sekaligus. Dari Pengabdian kepada masyarakat dan pemberian kuisioner yang telah dilakukan didapatkan bahwa teknisi AC dan kulkas telah memahami dengan baik pengaruh refrigerant pada lingkungan, pengaruh pada manusia atau teknisi sendiri, sejarah refrigerant, penanganan refrigerant yang telah terpakai serta keselamatan dan kesehatan.kerja dalam bekerja. Dengan Bimbingan Teknis kepada teknisi AC yang telah dilakukan, diharapkan dapat membantu mengurangi lepasnya refrigerant ke lingkungan dan membantu teknisi untuk dapat bekerja dengan mempertimbangkan keselamatan dan kesehatan kerja.
\end{abstract}

Kata kunci: Refrigerant, teknisi, AC, Kulkas

\begin{abstract}
The refrigerant was released into the environment will be damage into nature because of the chlorine content in it. In addition, refrigerant is also a toxic substance and will damage the central nervous system and cause negative cardiovascular effects. To reduce the release of refrigerant into the environment, in this community service of air conditioner and refrigerator technicians were chosen as partners. Air conditioner and refrigerator technicians are people who go directly to the field and come into direct contact with the refrigerant in the air conditioner and refrigerator. The collaboration with air conditioner technicians it is hoped that this activity will increase technicians will be get more knowledge of the refrigerant so it being reduce the refrigerant which will release. In this community service, air conditioner and refrigerator technicians in Kediri were given guidance through offline and online activities to provide technicians with understanding about refrigerants. Offline technical guidance is carried out in the workplace by following strict health protocols during the covid-19 pandemic. For the provision of materials that do not use equipment, technicians are given via zoom meeting to reach all technicians at once.
\end{abstract}


From community service and giving questionnaires, was found that air conditioner and refrigerator technicians had a good understanding of the effect of refrigerant on the environment, the effect on humans or the technicians themselves, the history of refrigerant, handling of used refrigerant and safety and health at work. With the technical guidance for air conditioner technicians that has been carried out, it is hoped it can help reduce the release of refrigerant into the environment and help technicians to be able to work with occupational health and savety.

Keywords: Refigerant, technician, air conditioner, refrigerator technicians

\section{PENDAHULUAN}

Analisis Situasi:

Di Kabupaten dan Kota Kediri terdapat lebih dari 10 tempat perbaikan AC dan kulkas (sistem Pendingin). Tempat perbaikan AC tersebut memiliki beberapa teknisi yang jumlahnya tidak sama. Jika terkumpul semuanya bisa lebih dari 100 teknisi. Jika masing-masing teknisi membuang refrigerant ke lingkungan, sebanyak 1 kaleng ukuran kecil saja (390 gram) maka jika diakumulasikan akan terhitung banyak sekali refrigerant yang terbuang ke lingkungan. Hal ini akan memicu terjadinya penipisan lapisan ozon. Hal ini tentunya memerlukan perhatian khusus mengingat teknisi AC adalah merupakan barisan terdepan yang langsung menangani refrigerant pada system pendingin di kediri raya. Banyak sedikitnya refrigerant yang terbuang ke lingkungan sekitar, tidak terlepas dari peranan teknisi AC. Untuk itu pendekatan dan pemahaman tentang refrigerant sangat dibutuhkan untuk mengurangi terbuangnya refrigerant ke udara.

Permasalahan Mitra:

Dari hasil observasi yang dilakukan, teknisi seringkali tidak menggunakan Alat Pelindung Diri saat bekerja. Hal ini akan sangat rawan terjadinya gangguan kesehatan akibat kerja yang tidak benar pada teknisi serta memungkinkan terjadinya penurunan produktifitas kerja. Selain itu sering terlihat teknisi melepaskan refrigerant ke udara saat melakukan vakum system pendingin

Kurangnya pemahaman dalam melakukan recovery dan kurangnya pemahaman tentang efek refrigerant juga bisa menjadi alasan yang kuat kenapa teknisi membuang refrigerant ke lingkungan. Beberapa teknisi utamanya yang masih baru, belum memiliki skill untuk melakukan recovery. Teknisi baru ada yang mendapatkan keterampilan dari SMK namun ada juga yang belum mendapatkan ketrampilan karena tidak didapatkan saat belajar di SMU atau MA. Keterbatasan peralatan juga mejadi faktor yang mempengaruhi terbuangnya refrigerant ke lingkungan sekitar.

\section{METODE}

Pada pengabdian kepada masyarakat ini mengupayakan peningkatan pengetahuan dan ketrampilan dengan bimbingan teknis pada kelompok teknisi AC dan kulkas. Bimbingan teknis diberikan kepada 10 s.d. 15 orang teknisi yang tersebar dikawasan Kediri Raya. Observasi kepada teknisi dilakukan untuk menentukan jenis pengabdian dan materi yang dibutuhkan. Diawal bulan dilakukan penilaian kerja teknisi dengan 
menggunakan penilaian Observasi menggunakan instrument Cek List Observasi (CLO) untuk menentukan materi yang diperlukan. Selanjutnya dilakukan penyusunan materi yang diperlukan baik dari aspek kognitif maupun Psikomotorik. Setelah materi dan peralatan semua siap, dilakukan pertemuan dengan teknisi untuk menyampaikan pengabdian yang dilakukan. Kegiatan dalam forum bersama dilakukan dalam 3 hari untuk menyampaikan materi namun dalam masa kegiatan pengabdian, tetap dilakukan tatap muka dengan teknisi di masing-masing tempat kerjanya. Beberapa materi seperti pengaruh refrigerant pada lingkungan, pengaruh refrigerant pada manusia, sifat dan sejarah refrigerant, serta penanganan refrigerant yang tidak terpakai disampaikan melalui tatap muka melalui zoom meeting. Beberapa teknisi yang tidak mampu mengoperasikan zoom juga dibantu oleh mahasiswa. Untuk mengukur tercapainya kegiatan, diakhir materi dilakukan penilaian menggunakan kuesioner yang diberikan kepada teknisi.

Penyampaian proses recovery refrigerant teknik alami seperti gambar 1 disampaikan untuk memberikan solusi penanganan refrigerant pada tempat kerja teknisi yang belum memiliki recovery pump. Beberapa teknisi yang sudah memiliki recovery pump diberikan materi tambahan yang lain bahkan ada yang menggunakan kompresor sebagai pengganti recovery pump. Sehingga dengan pemberian materi pada teknisi tidak sama tergantung kebutuhan.

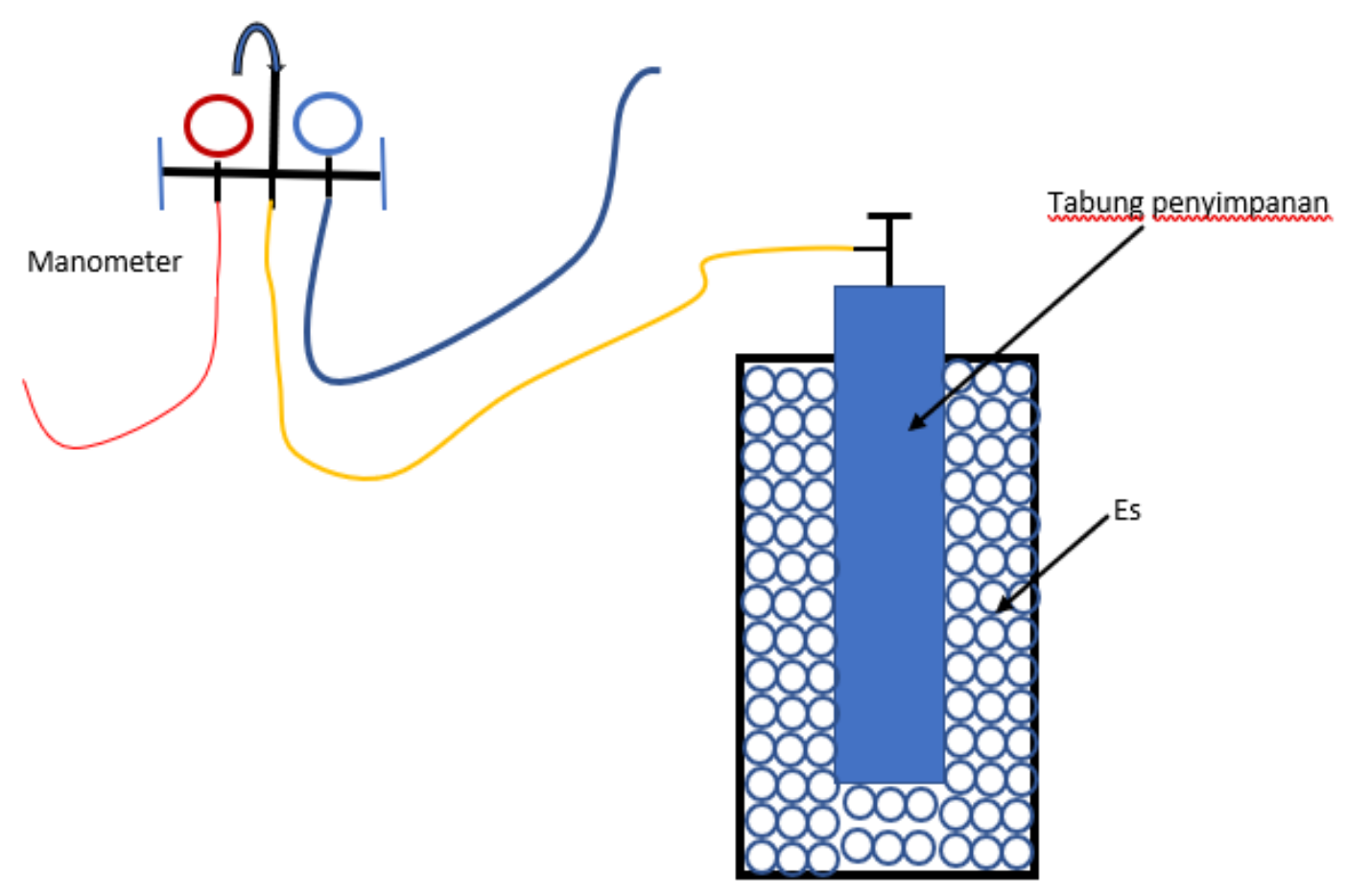

Gambar 1 Teknik Recovery alami

\section{WAKTU DAN TEMPAT PELAKSANAAN}

Waktu pelaksanaan program dilaksanakan pada bulan April 2021 sampai dengan bulan September 2021. 


\section{METODE PELAKSANAAN KEGIATAN}

1. Obeservasi

Observasi dilakukan untuk memperkenalkan diri sekaligus memahami penanganan refrigerant pada beberapa teknisi.

2. Pemberian materi virtual

Pemberian materi tentang efek refrigerant untuk kesehatan dan lingkungan dilakukan secara virtual menggunakan zoom meeting kepada lebih dari 10 teknisi untuk meningkatkan pemahaman tentang refrigerant dan penanganannya.

3. Penyampaian Demonstrasi ke beberapa teknisi yang memerlukan.

Setelah itu ditemukan beberapa hal penting yang hanya bisa dilakukan dengan demonstrasi pada benda yang sebenarnya dengan memperhatikan protocol kesehatan dan pembatasan peserta. Teknisi didatangi dan diberikan demonstrasi peralatan untuk melakukan penanganan refrigerant seperti terlihat pada gambar.2 dibawah

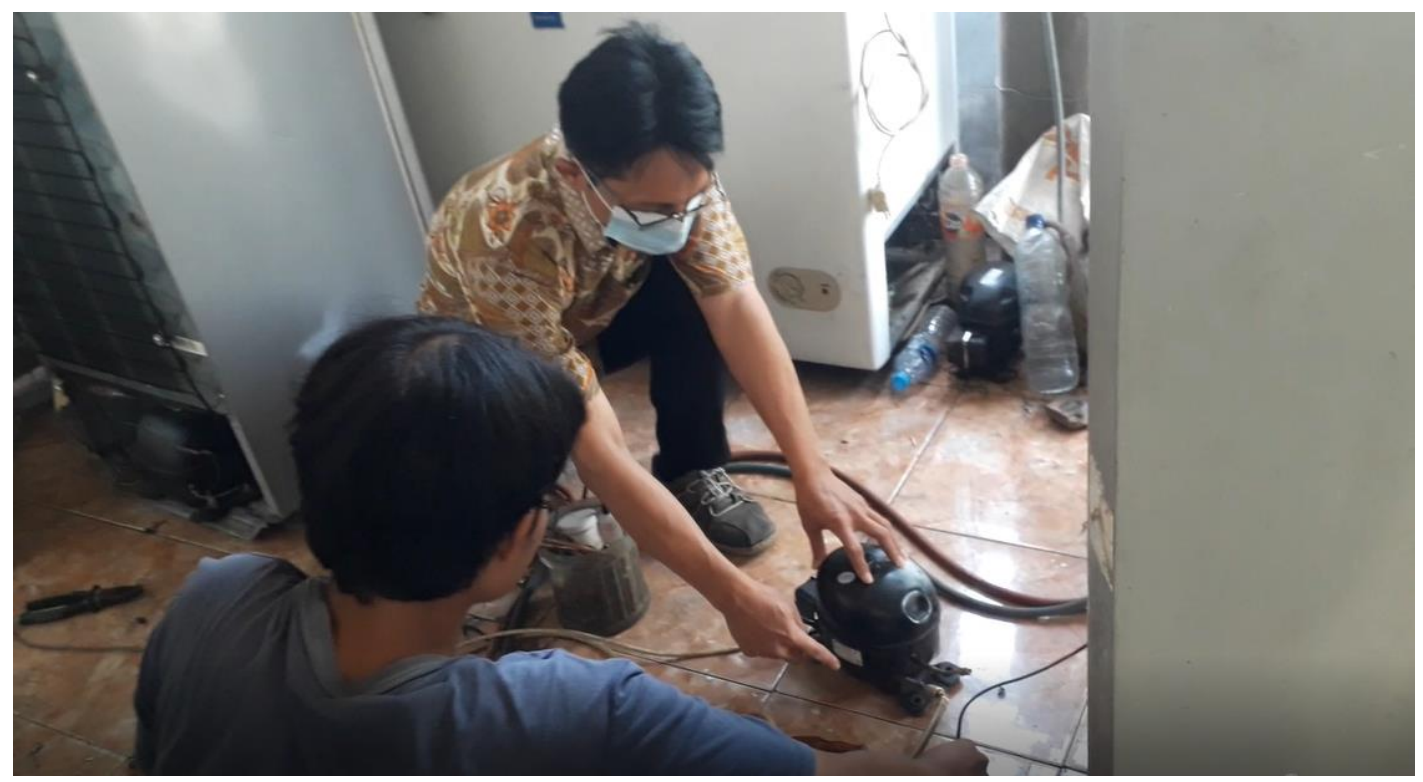

Gambar 2 Demonstrasi penanganan refrigerant

Pengisian kuesioner untuk menilai hasil bimbingan teknis dilakukan diakhir kegiatan. Hasil pengisian langsung diinterpretasikan untuk melihat capaian kegiatan yang dilakukan

\section{HASIL KARYA UTAMA DAN PEMBAHASAN}

Teknisi menunjukkan kepuasan terhadap pendampingan bimbingan teknis yang telah dilakukan. Indikasi kepuasan tersebut, dilihat dari hasil pengisian kuesioner oleh teknisi. Selain itu terlihat pula bahwa Teknisi juga yakin bimbingan teknis ini akan membantu menyelesaikan permasalahan yang ada. Mitra juga setuju bahwa bimbingan teknis yang diadakan meningkatkan kemandirian atau penambahan pengetahuan dan ketrampilan 
Dari kegiatan bimbingan teknis yang diadakan, dapat dipahami bahwa beberapa teknisi di kediri tidak memiliki recovery pump. Teknisi yang juga terjun dalam jual beli dan servis AC dan kulkas masih banyak yang belum memiliki recovery pump. Beberapa bahkan memodifikasi kompresor untuk digunakan untuk memvakum sistem.

Teknisi belum ada yang melakukan recyle refrigerant yang sudah terpakai untuk digunakan lagi ke dalam system pendingin. Hal ini dikarenakan beberapa teknisi masih lebih memilih melepas refrigerant ke lingkungan dan menggantinya dengan yang baru. Namun setelah bimbingan teknis selama ini diharapkan ada pengurangan tingkat pembuangan refrigerant yang telah dipakai ke lingkungan.

Perlunya dilakukan pengadaan recycle system untuk teknisi Kediri dan sekitarnya sehingga refrigerant masih digunakan lagi selain itu perlu pengaturan tempat penyimpanan refrigerant yang sudah terpakai.

\section{KESIMPULAN}

Dari interpretasi hasil kuesioner pada Pengabdian Kepada Masyarakat dalam bentuk bimbingan teknis yang telah dilakukan menunjukkan beberapa hasil sebagai berikut:

1. Pemahaman teknisi terhadap refrigerant cukup baik

2. Pemahaman teknisi dalam menangani refrigerant yang telah terpakai cukup baik

3. Teknisi merasa puas dengan pendampingan pada bimbingan teknis yang telah dilakukan.

4. Teknisi meyakini bimbingan teknis yang telah dilakukan ini akan membantu menyelesaikan permasalahan yang ada

Dengan kondisi teknisi yang belum banyak yang memiliki recovery pump semoga teknisi juga akan mampu menangani dengan metode sebaik mungkin. Semoga dengan kegiatan teknis ini mampu mengurangi lepasnya refrigerant ke lingkungan serta mampu mengingatkan teknisi untuk bekerja mengikuti Keselamatan dan Kesehatan Kerja.

\section{UCAPAN TERIMA KASIH}

Penulis mengucapkan terima kasih pada UPT Politeknik Negeri Malang yang telah mendukung pelaksanaan bimbingan teknis ini. Tidak lupa kami ucapkan terima kasih pada mahasiswa yang ikut membantu kelancaran bimbingan teknis ini.

\section{DAFTAR PUSTAKA}

Bukola O. Bolaji. 2020. Theoretical assessment of new low global warming potential refrigerant mixtures as eco-friendly alternatives in domestic refrigeration systems Elsevier Scientific African 10 (2020) e00632

Butler J. and Montzka S. (2020). The NOAA Annual Greenhouse Gas Index (AGGI). NOAA Global Monitoring Laboratory/Earth System Research Laboratories

Berwald, Juli (2019-04-29). One overlooked way to fight climate change, Dispose of old CFCs. National Geographic - Environment. Retrieved 2019-04-30.

EPA. Protection of Stratospheric Ozone: Hydrocarbon Refrigerants (PDF). Environment Protection Agency. Retrieved 5 August 2018. 
Harris, Catharine. Anti-inhalant Abuse Campaign Targets Building Codes: 'Huffing' of Air Conditioning Refrigerant a Dangerous Risk." The Nation's Health. American Public Health Association, 2010. Web. 05 Dec.2010

Jason P. Caplan, M.D., Amanda E. Pope, M.S., Christy A. Boric, L.M.S.W., Dawn A. Benford, P.M.H.N.P.-B.C. 2012. Air Conditioner Refrigerant Inhalation: A Habit with Chilling Consequences. Elsevier Psychosomatics 273-276 